\title{
Wet clay adhesion to antistick coatings: Effects of binder type and surface roughness
}

Fasano, Andrea; Madaleno, Liliana ; Daviðsdóttir, Svava; Jensen, Lars S.; Palasi, Josep; E. Weinell, Claus; Dam-Johansen, Kim; Kiil, Søren

Published in:

Journal of Coatings Technology and Research

Link to article, DOI:

$10.1007 / \mathrm{s} 11998-019-00240-3$

Publication date:

2020

Document Version

Peer reviewed version

Link back to DTU Orbit

Citation (APA):

Fasano, A., Madaleno, L., Daviơsdóttir, S., Jensen, L. S., Palasi, J., E. Weinell, C., Dam-Johansen, K., \& Kiil, S. (2020). Wet clay adhesion to antistick coatings: Effects of binder type and surface roughness. Journal of Coatings Technology and Research, 17, 69-79. https://doi.org/10.1007/s11998-019-00240-3

\section{General rights}

Copyright and moral rights for the publications made accessible in the public portal are retained by the authors and/or other copyright owners and it is a condition of accessing publications that users recognise and abide by the legal requirements associated with these rights.

- Users may download and print one copy of any publication from the public portal for the purpose of private study or research.

- You may not further distribute the material or use it for any profit-making activity or commercial gain

- You may freely distribute the URL identifying the publication in the public portal 


\title{
Wet clay adhesion to antistick coatings: Effects of binder type and surface roughness
}

\author{
Andrea Fasano $^{\mathrm{a}}$, Liliana Madaleno ${ }^{\mathrm{b}}$, Svava Davidsdottir ${ }^{\mathrm{b}}$, Lars S. Jensen ${ }^{\mathrm{c}}$, Josep \\ Palasi $^{\mathrm{d}}$, Claus E. Weinell ${ }^{\mathrm{a}}$, Kim Dam-Johansen ${ }^{\mathrm{a}}$, Søren Kiil ${ }^{\mathrm{a} *}$. \\ a: CoaST, Department of Chemical and Biochemical Engineering, Technical \\ University of Denmark, DTU, Building 229, DK-2800 Kgs. Lyngby, Denmark \\ b: Hempel A/S, Lundtoftegårdsvej 91, DK-2800 Kgs. Lyngby, Denmark \\ c: FLSmidth A/S, Vigerslev Allé 77, 2500-DK Valby, Denmark \\ d: Hempel A/S, Carretera de Sentmenat 108, 08213 Polinya, Spain
}

\begin{abstract}
The handling of sticky raw material can cause problems during operation of process equipment in the cement production industry. These handling problems are generally observed when raw material (e.g. wet clay) sticks to machine walls and causes blockage of outlets. This leads to frequent production shutdowns and expensive cleaning operations. In this work, the effects of surface material and process parameters on the friction forces between wet clay and surface were investigated. Various surface materials and clay impact speeds were investigated.

The results demonstrate that not only the equipment surface material but also the surface roughness influences the observed frictional behavior. The ranking of the materials in terms of effective static friction coefficients fell in two groups with equal performance within the group: 1) Two Teflon-based coatings (Accofal 2G54 and Accolan LB), polished AISI 304 stainless steel, Matrox lining, and a polyurethanebased coating (best performing surfaces), 2) Mild steel, a silicone-based coating, and AISI 304 stainless steel (worst performing surfaces). However, the friction coefficients of the two groups only varied by a factor of two, suggesting that adhesion of wet clay to surfaces is difficult to avoid by the use of coatings.
\end{abstract}

\footnotetext{
* Corresponding author. Telephone: +45 452528 27. Email: sk@kt.dtu.dk
} 
Keywords: Antistick coatings, steel, friction measurements, wet clay, cement industry.

\section{Introduction}

During operation of unit operations in the cement industry, adhesive raw materials (wet clay and limestone) tend to stick on equipment surfaces. An example is the inside walls of plant transfer chutes following conveyor belts, where blockage of outlets and unpredictable raw material build-up are often observed. This can lead to frequent production shutdowns. In addition, cleaning operations can be difficult and time consuming.

The exposed surfaces can be equipped with low friction linings that decrease the raw material build-up and are able to withstand the abrasive pressure (so-called impact zone). However, raw material build-ups are also observed in secondary environments that are less abrasive (so-called splashing zone), where less costly antistick organic coatings may be used.

No studies on this particular topic have been found in the scientific literature.

In the present work, experiments with coated and uncoated (steel) surfaces are investigated. A new type of pilot plant, simulating the tribological behaviour of raw materials impacting the cement production equipment wall, is used. In the setup, the moist raw material adheres to the sample surface and the force required to remove it is measured. The effects on the effective static friction coefficient of coating binder type and coating roughness are quantified. 
1.1 Mechanisms of wet clay adhesion to surfaces

The adhesive build-up of granular material occurs when the raw material is wet. This implies that surface tension plays a fundamental role [1-2]. In wet clay, the stickiness is a function of the water content with a maximum typically appearing somewhere between 10 and $20 \mathrm{wt} \%$ [2-3].

Five different clay-water states, as illustrated in Fig. 1, have been observed:

- $\quad$ Dry: there is no or very little water, no liquid bridges are formed.

- Pendular: Liquid bridges are formed, which hold the grains together in the granular material.

- $\quad$ Funicular: The liquid fully saturates some pores, while others are filled with air.

- $\quad$ Capillary: The liquid fills all the voids between particles while capillarity is responsible for suction of surface liquid into the pores.

- Slurry: at the surface there is no capillary action as particles are fully immersed in the liquid forming a slurry.

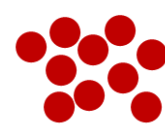

Dry

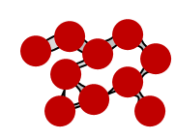

Pendular

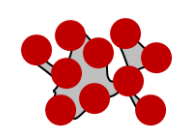

Funicular

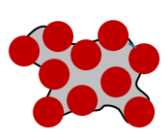

Capillary

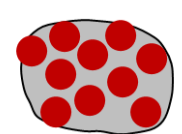

Slurry

Water content

Figure 1. Different states of a granular media at increasing water content from dry state to slurry. The grains are brown and the interstitial liquid grey. Redrawn from Mitarai and Mori [2]. 
The states of major interest are the ones from pendular to capillary, because stickiness and cohesion of wet granular material can stem from both liquid bridges between two grains and capillary suction at the liquid-air interface. This maximum stickiness may appear at a rather wide range of possible water contents, depending on the type of clay (e.g. minerals ) [3-4]. For the clay used in this work, the critical water content is between 15 and $22 \%$.

The surface roughness is another important parameter because clay particles have the ability to interlock in-between the grooves of a exposed surface. For clay-steel systems, investigated in the shear box type of apparatus [3,5-7], this mechanism was found to be significant [8].

\section{Pilot plant design and measurement system}

A pilot plant was designed and built to enable the measurement of effective static friction coefficients of wet clay on metal, lining and coating surfaces. The setup simulates that of a wall in the so-called splashing zone inside transfer chutes (connecting assembly belts) in cement producing plants. The abrasion pressure in this zone is significantly lower than that in the high impact zone, where most clay and rocks on the assembly belt will come in direct contact with the wall. In a full-scale plant, the force acting on the adhesive wet clay (after impact) is that of gravity. In the pilot plant, this is simulated with a centrifugal force acting on a clay lump adhering to a spinning disk.

An important feature of the setup is that it takes into account the actual impact (and subsequent adhesion) of wet granular material on a surface, i.e. the apparatus is able to account for the cement raw material processing dynamics. 


\subsection{Pilot plant design}

The new setup used to measure the frictional/adhesional properties of the wet granular material-coated/uncoated disk system is shown in Fig. 2.

a)

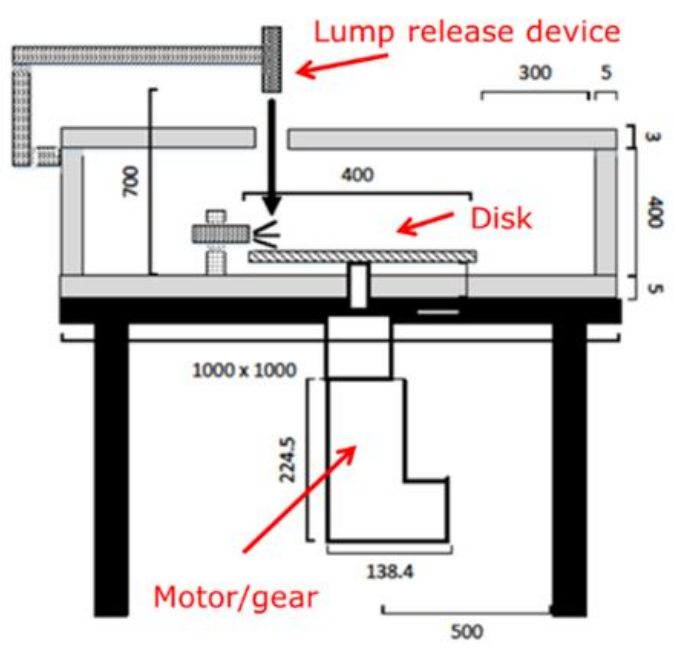

b)

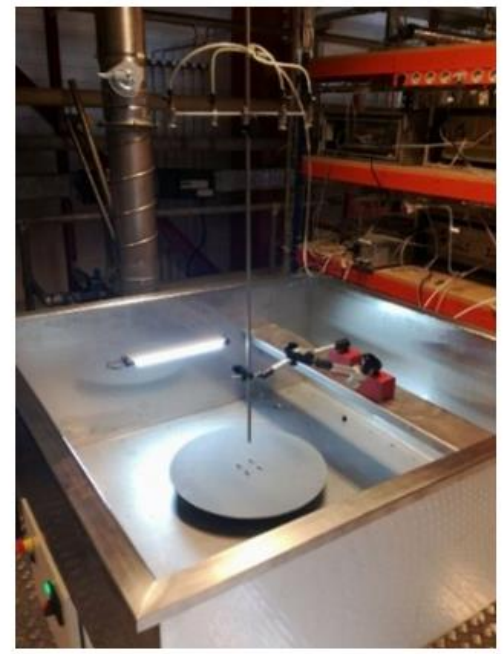

Figure 2: a) Schematic illustration of spinning disk pilot plant (dimensions are in $\mathrm{mm})$. b) Photo of the pilot plant.

The setup consists of a metal box containing a lump release device, where the height can be varied, and a 400-mm diameter spinning disk where the angular velocity can be controlled. The disk can be made of a metal, a stiff high molecular weight polyethylene lining (Matrox), or a coated metal substrate.

The lump release device consists of a magnetic arm that holds a 4-arm stand. Each arm has a suction cup where the granular material lump can be held in place (when vacuum is applied) and subsequently released (when pressurised air is turned on). The switch from vacuum to pressurised air is obtained by opening a bypass valve. The motor and gear box system were provided by JVL A/S. The motor is a step motor MAC400 D-5 with brake and the gear box is a planetary HTRG10. The motor provides an effect of $400 \mathrm{~W}$ and the gear ratio is 1:10 (the actual rotation of the disk 
(and gear shaft) is $1 / 10$ of the rotation of the motor). The maximum motor rotation is $3500 \mathrm{rpm}$, geared down to $350 \mathrm{rpm}$ for the spinning disk. To transfer commands and measurements between computer and motor, the commercial software MacTalk from JVL A/S is used. The minimum acceleration of the motor is $271 \mathrm{rpm} / \mathrm{s}$. This means that the maximum speed would be reached in approximately 13 seconds, leading to significant uncertainty in the tribological measurements as all release times fall within a few seconds. A computer program was therefore developed to vary the angular speed of the disk from 0.0 to $350.0 \mathrm{rpm}$ in 70 seconds at a constant angular acceleration of $5.0 \mathrm{rpm} / \mathrm{s}$. This was done by increasing the set point angular velocity of the motor by $50 \mathrm{rpm}$ each second. The specified torque and load of the motor were optimised and set to $10 \%$ and 1.0000 , respectively, to minimise the vibration of the motor while spinning. The actual angular velocity of the disk and the calculated velocity were compared at different time steps in the calibration phase. For calibration of the experimental apparatus when galvanised mild steel disks (thickness of $5 \mathrm{~mm}$ ) were used, five repetitions were done taking at least 6 samples from each of them. On average, the calculated velocity had a delay of 0.3 seconds, which is comparable to a stopwatch operator response time delay when a clay lump detaches from the spinning disk. A similar approach was used for stainless steel disks and a Matrox disk (thickness of $12 \mathrm{~mm}$ ). Considering the fast drying because of the spinning, 70 seconds is the maximum duration of the experiment as it ensures negligible drying of the wet clay during the experiment. This is important to avoid significant changes in surface tension effects and stickiness of the granular material, which strongly depends on the surface water content. To avoid evaporation and increase experimental time, a constant humidity chamber would be necessary, but that was not attempted in the present work. 


\subsection{Calculation of the effective static friction coefficient}

The clay lump experiences an acceleration consisting of radial and tangential components. The angular acceleration is assumed to be constant throughout the experiment. Since the angular speed is increasing over time, there is a tangential acceleration in addition to the radial acceleration. If there is no relative movement between wet granular material lump and spinning disk, the force of static friction is:

$$
\begin{gathered}
\left|F_{\text {s,friction }}\right|=\sqrt{F_{\text {radial }}^{2}+F_{\text {tangential }}^{2}}=\sqrt{\left(m a_{\text {radial }}\right)^{2}+\left(m a_{\text {tangential }}\right)^{2}} \\
=m \sqrt{\left(\frac{v^{2}}{r}\right)^{2}+(r \alpha)^{2}}=m \sqrt{\left(\omega^{2} r\right)^{2}+(\alpha r)^{2}} \\
=m r \sqrt{\omega^{4}+\alpha^{2}}
\end{gathered}
$$

at any time $\mathrm{t}$ while the cylinder is spinning. $m$ is the mass of the clay lump on the disk, $r$ denotes the distance of the impact point from rotational axis of the spinning disk. $v$ and $a$ represent the velocity and the acceleration, respectively, whereas $\omega$ and $\alpha$ are the angular velocity and acceleration, respectively.

At release (an instant before the first movement) of the clay lump from the disk, the static friction force is:

$$
\left|F_{s, \text { friction }}\right|=\mu_{s, e f f}|N|
$$

with the normal force $N$ being:

$$
|N|=m g
$$

Therefore, the static force balance gives:

$$
\left|F_{s, \text { friction }}\right|=\mu_{s, \text { eff }} m g=m r \sqrt{\omega^{4}+\alpha^{2}}
$$

in which $\mu_{s, e f f}$ denotes an effective static friction coefficient [12], here accounting for all the stickiness contributions (frictional and adhesional). 
Rearranging eq (4) yields the following expression for the effective static friction coefficient:

$$
\mu_{s, e f f}=\frac{r}{g} \sqrt{\omega^{4}+\alpha^{2}}
$$

where $\alpha$ indicates a constant angular acceleration and $\mathrm{g}$ is the gravitational acceleration. Notice, that the radial distance of the lump from the centre of the disk, $r$, can vary in the experiments.

\section{Steel disks, lining and coatings}

The spinning disk (40 $\mathrm{mm}$ diameter, $5 \mathrm{~mm}$ thickness) can be made of galvanised mild steel, stainless steel (AISI 304) or commercial Matrox (machine cut from a 12-mm thick piece of ultrahigh molecular weight polyethylene lining from Röchling, Germany). The steel disks had different roughness levels (from polishing or sandblasting). The arithmetic average roughness, $\mathrm{Ra}$, of a spinning disk was measured with the mobile roughness measuring instrument MarSurf PS 10 by Mahr GmbH. Calibration was performed at least once a day when the instrument was in use. Coating dry film thickness was measured using an Elcometer 355 magnetic gauge. The coating materials shown in Table 1 were used on sandblasted steel disks. 
Table 1. Coatings used on the spinning steel disks.

\begin{tabular}{|c|c|c|c|}
\hline Coating name & Supplier & $\begin{array}{c}\text { Targeted coating } \\
\text { thickness }\end{array}$ & Coating type \\
\hline Accolan LB & Accoat A/S, Denmark & $10-50 \mu \mathrm{m}$ & $\begin{array}{l}\text { Thermoplastic } \\
\text { fluoropolymer }\end{array}$ \\
\hline Accofal 2G54 & Accoat A/S, Denmark & $30-80 \mu \mathrm{m}$ & $\begin{array}{l}\text { Low roughness } \\
\text { thermoplastic } \\
\text { fluoropolymer }\end{array}$ \\
\hline Polyurethane (PU) & Hempel A/S, Denmark & $200 \mu \mathrm{m}$ & $\begin{array}{l}\text { Thermoset basecoat } \\
\text { with pigments and } \\
\text { various additives }\end{array}$ \\
\hline Silicone & Hempel A/S, Denmark & $\begin{array}{l}\text { First layer } 150 \mu \mathrm{m} \\
\text { Second layer } 50 \mu \mathrm{m}\end{array}$ & $\begin{array}{l}\text { Thermoset coating } \\
\text { containing pigments } \\
\text { and various } \\
\text { additives }\end{array}$ \\
\hline
\end{tabular}

The PU coating is a 2-component polyurethane with high hydrophobicity, consisting of a standard flexible polyester polyol and cured with a standard isocyanate. It contains standard pigments and particular extenders and solvents to impart high hydrophobicity to the coating. The curing agent was added immediately before spraying (about $25.7 \%$ of the base coat by weight) to enable easy spraying (low viscosity). After spray application, the coating was allowed to cure for two weeks.

The silicone coating was prepared first as base coat followed by a top coat, applied one day after the base coat. The coating is a 1-component, room temperature vulcanizing silicone (polydimethylsiloxane), with pigment and curing agent components designed for enhancing surface hydrophobicity. After spraying of the top coat, the coating system was allowed to cure (with humidity) for two weeks. 
Additional details of the commercial, fluoropolymer-based coatings (Accolan LB and Accofal 2G54) were not available.

All disks prepared are shown in figure 3 together with the rougness values measured.
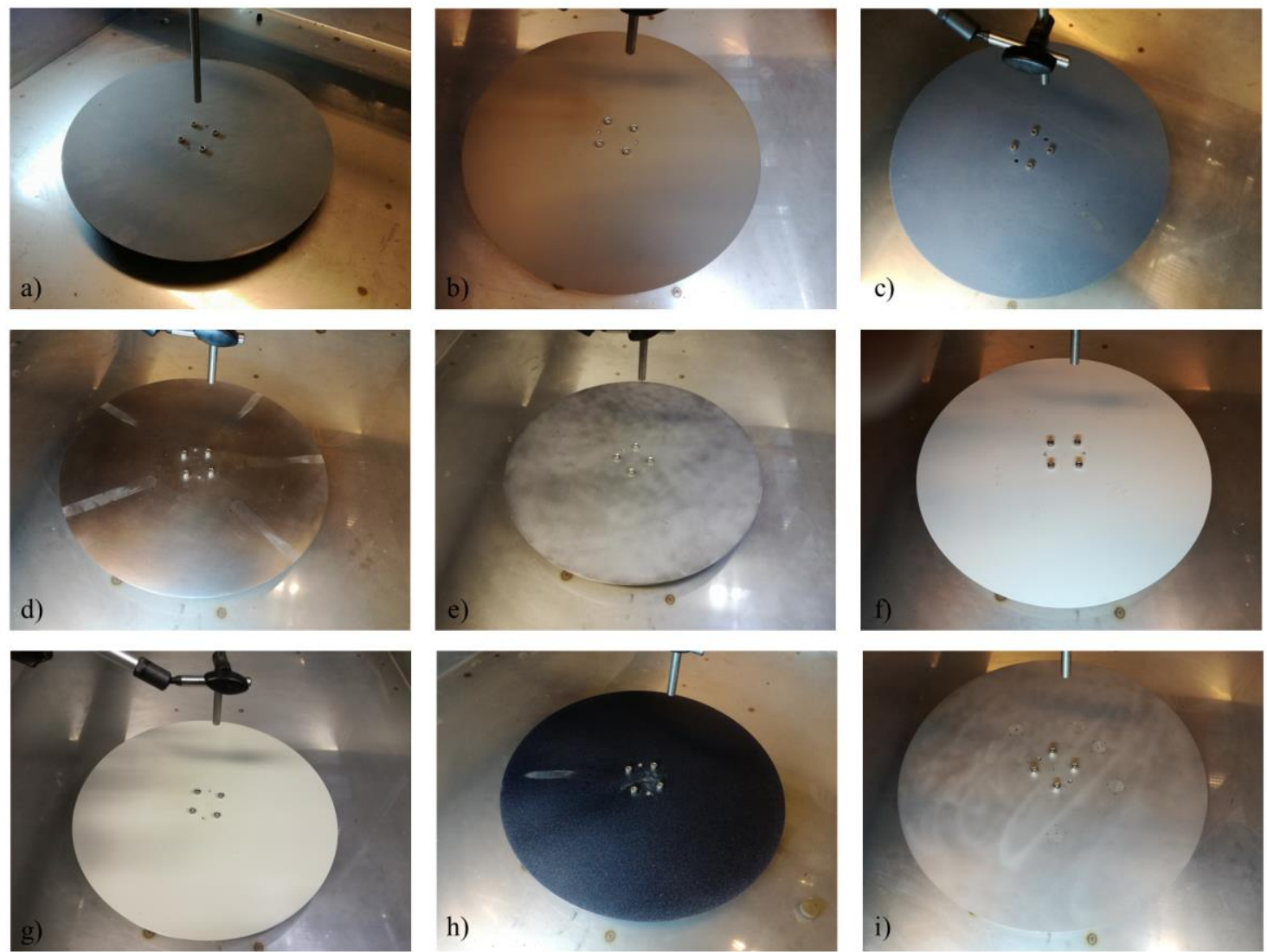

Figure 3. Photos of the surface materials investigated: a) Galvanised mild steel disk.

b) Accolan LB. c) Matrox disk. d) AISI 304 stainless steel (finely polished): $\mathrm{Ra}=$ $0.33 \pm 0.02 \mu \mathrm{m}$. e) Mild steel (sandblasted): $\mathrm{Ra}=10.63 \pm 0.94 \mu \mathrm{m}$. f) Polyurethane: $\mathrm{Ra}$ $=2.91 \pm 0.21 \mu \mathrm{m}, \mathrm{DFT}=167.4 \pm 25.2 \mu \mathrm{m} . \mathrm{g})$ Silicone: $\mathrm{Ra}=1.12 \pm 0.16 \mu \mathrm{m}, \mathrm{DFT}=$ 198.5 $\pm 27.2 \mu \mathrm{m} . \mathrm{h})$ Accofal 2G54: Ra 1.04 $\pm 0.11 \mu \mathrm{m}, \mathrm{DFT}=61.3 \pm 1.5 \mu \mathrm{m}$. i) AISI 304 stainless steel (sandblasted): $\mathrm{Ra}=1.57 \pm 0.14 \mu \mathrm{m}$. 


\subsection{Contact angle measurements}

Advancing contact angles of the surfaces were measured on an OCA 20 from Data Physics Instruments $\mathrm{GmbH}$, using ultra-clean millipore water droplets and the socalled Sessile Drop method. Three repetions were recorded at three different positions on each surface at room temperature. Prior to the measurements, each sample was gently cleaned with ethanol to remove any dust present on the surfaces.

\section{Characterization of the clay used}

Only one clay type, so-called Slantzy clay, was used in the investigation. In this section, various characterization analyses done on the clay are discussed.

4.1 X-ray analysis of the clay

In table 2, an x-ray analysis of the wet Slantzy clay is shown. It can be seen that most of the clay is made up of $\mathrm{SiO}_{2}$ (sand-like material). 
Table 2. XRF analysis on slantzy clay. The samples were prepared using a Katanax K2 (for automated preparation that captures sulphur in the sample). Note, that Loss on Ignition (LOI) at $975{ }^{\circ} \mathrm{C}$ accounts for $6.94 \% \mathrm{w} / \mathrm{w}$.

\begin{tabular}{ll}
\hline Compound & Mass fraction [\%] \\
\hline $\mathrm{SiO}_{2}$ & 63.07 \\
$\mathrm{Al}_{2} \mathrm{O}_{3}$ & 12.41 \\
$\mathrm{Fe}_{2} \mathrm{O}_{3}$ & 4.74 \\
$\mathrm{CaO}$ & 4.21 \\
$\mathrm{MgO}$ & 2.85 \\
$\mathrm{Mn}_{2} \mathrm{O}_{3}$ & 0.09 \\
$\mathrm{TiO}_{2}$ & 0.70 \\
$\mathrm{P}_{2} \mathrm{O}_{5}$ & 0.14 \\
$\mathrm{~K}_{2} \mathrm{O}$ & 3.61 \\
$\mathrm{Na}_{2} \mathrm{O}$ & 0.99 \\
$\mathrm{SrO}_{\mathrm{SO}}$ & 0.02 \\
$\mathrm{LOI}_{3} 975{ }^{\circ} \mathrm{C}$ & 0.10 \\
$\mathrm{TOTAL}^{2}$ & 6.94 \\
& 99.87
\end{tabular}

4.2 Particle size analysis of the clay

The particle size distribution (PSD) of Slantzy clay, diluted (and partly dissolved) in demineralized water and measured on a Malvern Mastersizer, is shown in figure 4. It is evident (when comparing with the values in the caption of figure 3 ) that a high fraction of the particles has a size comparable to the average roughness values of the disk surfaces. 


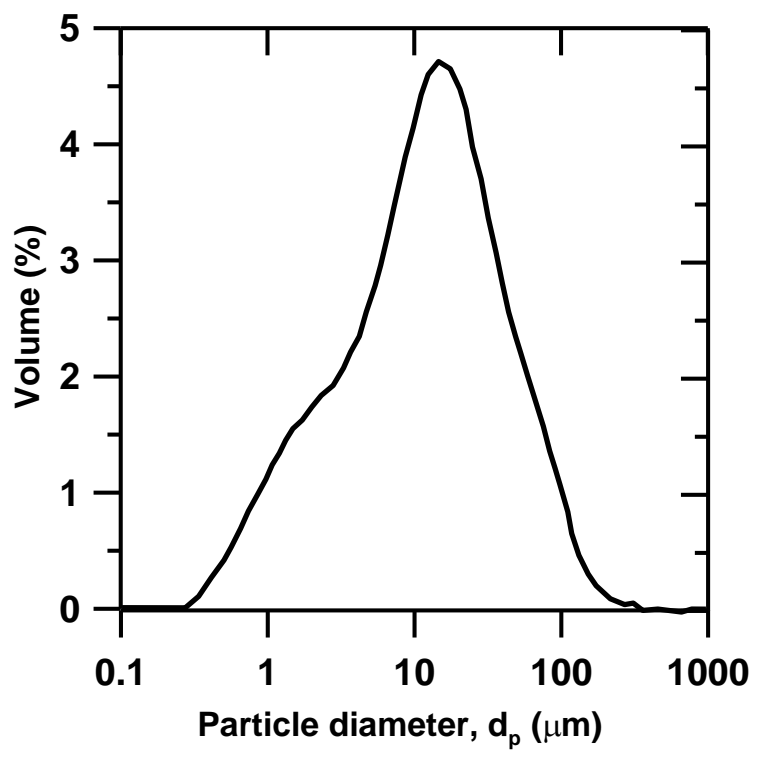

Figure 4. Particle size distribution (volume-based) of Slantzy clay "dissolved" in demineralized water.

\subsection{Chemical analysis of clay}

In Table 3, a chemical analysis of Slanzy clay for selected elements is provided. For this analysis, the samples were digested in an Anton Paar Multiwave 3000 with fluoric acid (complete digestion). 
Table 3. Results of ICP/OES analysis on slantzy clay. Note that the abundant element Si (see Table 2) was not measured in this analysis.

\begin{tabular}{ll}
\hline Element & Concentration \\
& {$[\mathrm{mg} / \mathrm{kg}]$} \\
\hline $\mathrm{As}$ & $<10$ \\
$\mathrm{Ba}$ & 488 \\
$\mathrm{Cd}$ & $<1$ \\
$\mathrm{Co}$ & 12 \\
$\mathrm{Cr}$ & 62 \\
$\mathrm{Cu}$ & 18 \\
$\mathrm{Mn}$ & 571 \\
$\mathrm{Ni}$ & 27 \\
$\mathrm{~Pb}$ & $<10$ \\
$\mathrm{Sb}$ & $<10$ \\
$\mathrm{Se}$ & $<5$ \\
$\mathrm{Ti}$ & $<5$ \\
$\mathrm{~V}$ & 66 \\
$\mathrm{Zn}$ & 60 \\
\hline
\end{tabular}

\subsection{Mineral composition of clay}

In table 4, the mineral composition of Slantzy Clay is shown. Note, that an estimation of the mineral distribution in the clay is provided, as a precise evaluation is difficult to estabilish due the presence of low symmetry structures that yields complex diffractograms. All samples were analyzed by using $10 \%$ by weight of $\mathrm{TiO}_{2}$ (Anatase crystal) as the internal standard. It can be seen that quartz is the most abundant mineral. 
Table 4. Results of XRD analysis of Slantzy clay (rounded to whole numbers).

\begin{tabular}{|c|c|}
\hline Mineral & Weight per cent \\
\hline Quartz $\left[\mathrm{SiO}_{2}\right]$ & 38 \\
\hline Dolomite $\left[\mathrm{CaMg}\left(\mathrm{CO}_{3}\right)_{2}\right]$ & 14 \\
\hline Muscovite $\left[(\mathrm{KF})_{2}\left(\mathrm{Al}_{2} \mathrm{O}_{3}\right)_{3}\left(\mathrm{SiO}_{2}\right)_{6}\left(\mathrm{H}_{2} \mathrm{O}\right)\right]$ & 23 \\
\hline Chamsosite $\left[\left(\mathrm{Fe}^{2+}, \mathrm{Mg}\right)_{5} \mathrm{Al}\left(\mathrm{AlSi}_{3} \mathrm{O}_{10}\right)(\mathrm{OH})_{8}\right]$ & 6 \\
\hline Albite $\left[\mathrm{NaAlSi}_{3} \mathrm{O}_{8}\right]$ & 16 \\
\hline Amorphous & 4 \\
\hline
\end{tabular}

\subsection{Rheological analysis of clay}

The rheological behavior of natural, wet Slantzy clay was measured using a Discovery Hybrid Rheometer (DHR-2, TA instruments) with a parallel-plate configuration at laboratory conditions (around $20^{\circ} \mathrm{C}$ ). In figure 5, the rheological measurements are shown. It can be seen that the clay is a visco-elastic material with a shear ratedependent viscosity (i.e. shear-thinning).

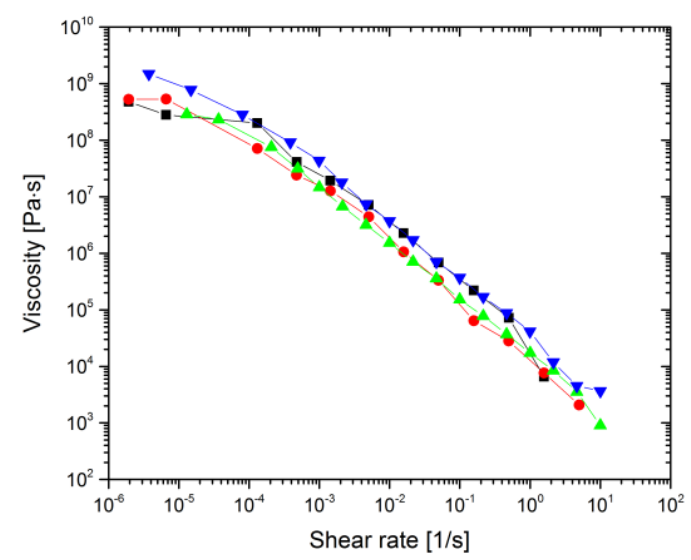

Figure 5. Rheological flow sweep curve from a shear rate of $10^{-5}$ to $10 \mathrm{~s}^{-1}$ for Slantzy clay samples. Four repetitions are shown. The average water content in the samples was $20.4 \mathrm{wt} \%$. 
4.6 Water content of clay

The water content of clay is a very important parameter when considering wet clay adhesion to surfaces. In Fig. 6, experimental drying series for Slanzy clay are provided. The top figure shows the full series, whereas the bottom one zooms in on the small changes observed after the first five minutes of drying. The water content is about $20 \mathrm{wt} \%$ for all samples used.
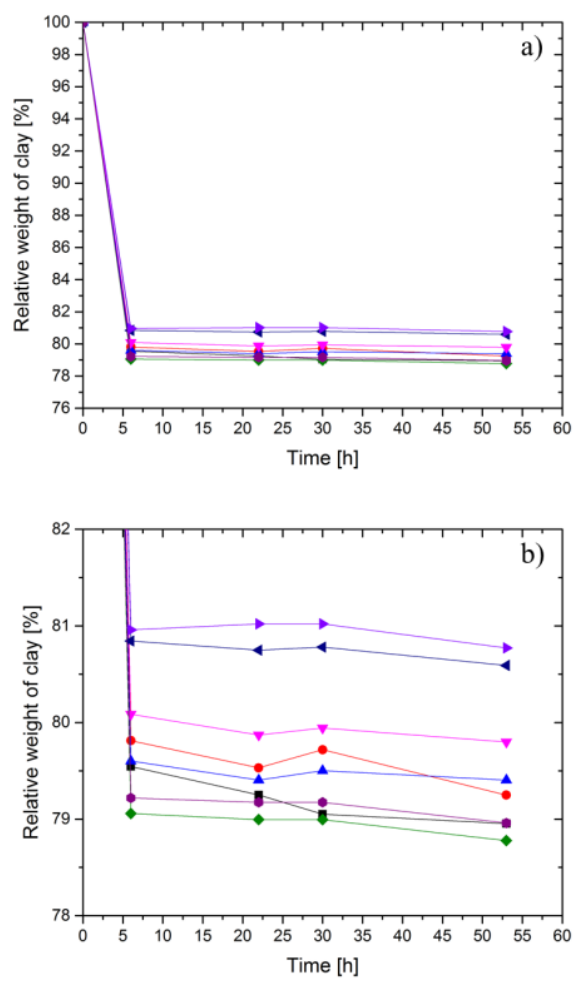

Figure 6. a) Weight relative to the initial humid weight (natural Slantzy clay) throughout the drying experiments (54 hours). Eight repetitions were performed.Temperature was increased to $215^{\circ} \mathrm{C}$ after complete drying $\left(130{ }^{\circ} \mathrm{C}, 30\right.$ hours) to ensure that all surface water in the sample was removed. 
In Fig. 7, the effects on drying of initial clay mass are shown. No strong influence of initial clay mass was found.

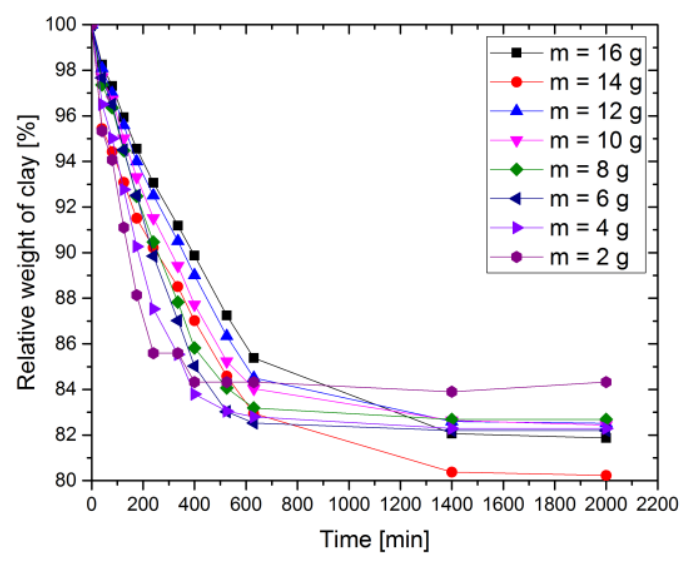

Figure 7. Weight of drying clay spheres relative to the initial wet weight. Temperature was ambient and the clay type natural Slantzy.

\section{Results and discussion}

A series of experiments was conducted in the pilot plant to investigate the influence of surface roughness and composition on the antistick properties of selected coatings, metals, and a rubber lining.

\section{Effect of clay lump mass}

In Fig. 8, the effects on the static effective friction coefficient of clay lump mass for two free fall heights on galvanized mild steel are shown. The top figure represents a free fall height of $0 \mathrm{~cm}$, whereas the bottom one shows results for $100 \mathrm{~cm}$. It can be seen that if there is no free fall (i.e. no deformation of the clay lump), prior to the disk experiment, the friction coefficient is independent of the clay lump mass. On the other hand, in the presence of a free fall, the friction coefficient first decreases with clay lump mass, then becomes constant above about $8 \mathrm{~g}$. This observation can be attributed 
to deformation of the clay lump upon impact, whereby clay is forced into the tiny crevices of the top layer of the steel. The values obtained in the bottom plot are much higher than those in the top plot so the impact has a strong effect on the results. The reason why the friction coefficient decreases with increasing impact strength (mass) up to $8 \mathrm{~g}$ could be due to a lack of proportionality between clay sample mass and contact area, so that the position of the centre of mass of the clay lumps, after impact, is a function of the clay mass ifself (i.e. the small lumps have relatively lower positioned centres of mass and are therefore more difficult to remove). However, it may also be related to the existence of a domain where the apparent contact area is closely comparable to the real contact area [9]. Such a domain could be reached due to the softness of the clay, which helps the sample to fully exploit and adhere to the disk surface when an impact force is applied (i.e. free fall height of $\mathrm{h}=100 \mathrm{~cm}$ ). A non-linear increase of the frictional force with the normal force has been observed for other systems, i.e. steel/teflon [10] and particularly in soft materials such as polymers and elastomers [9].

As a final note, it is evident from Fig. 8, that measurements should be done with masses between 8 and $16 \mathrm{~g}$ in order to obtain a stable value of the friction coefficient and this was done in all subsequent experiments. 

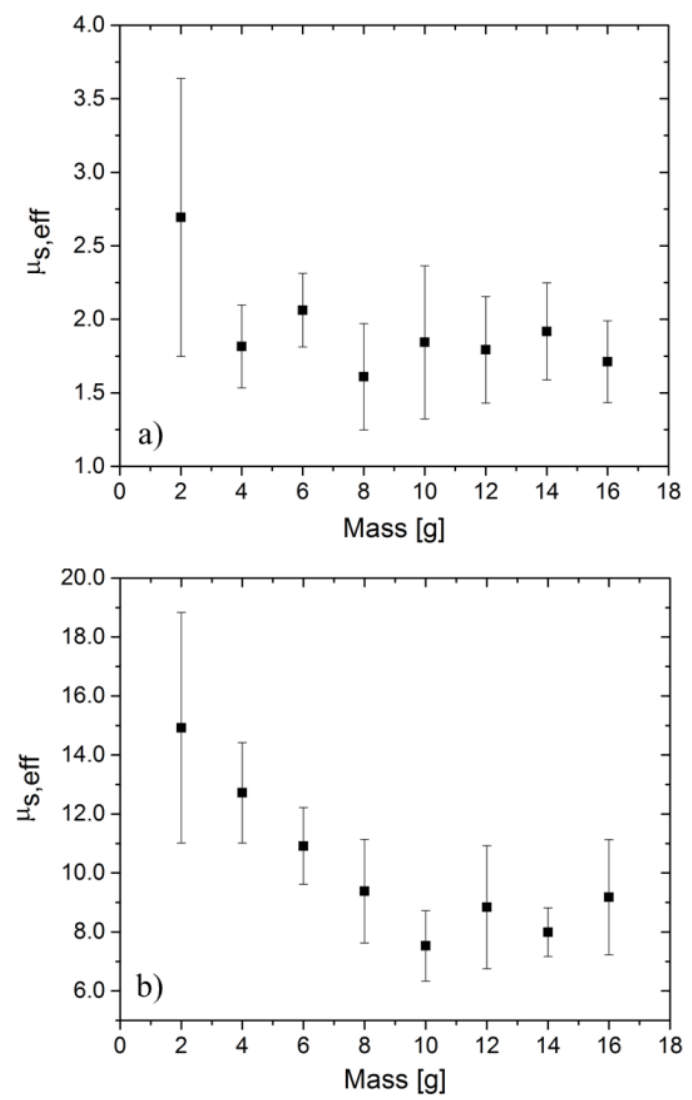

Figure 8. Effective static friction coefficient for different clay lump masses and free fall heights (surface: galvanized mild steel): a) free fall height $\mathrm{h}=0 \mathrm{~cm}(\mathrm{~T}=24.7-26.5$ ${ }^{\circ} \mathrm{C}, \mathrm{RH}=44.8-54.0 \%, 5$ repetitions $\left.) . \mathrm{b}\right)$ free fall height $\mathrm{h}=100 \mathrm{~cm}\left(\mathrm{~T}=23.6-27.5{ }^{\circ} \mathrm{C}\right.$, $\mathrm{RH}=28.0-47.7 \%, 5$ repetitions $).$

\section{Effect of repositioning of clay lump}

To explore the effect of clay remains in crevises on the mild steel surface on the friction coefficient, clay lumps were first allowed to fall from $100 \mathrm{~cm}$, whereafter they were gently removed while maintaining the same clay-surface contact area. The deformed clay samples were repositioned on the disk, either at the same or at another "clean" position, and measurements conducted. The results are shown in Fig. 9, where it can be seen that potential clay remains have no influence on the friction coefficient measured. This result is important for real life evaluations of a surface, where clay 
lumps may attach to a surface and subsequently be removed due to gravitational pull, making room for yet another wet clay lump to attach. The experiment was only conducted for the mild steel surface, and only for $\mathrm{H}=0$ during repositioning, due to difficulties in making the clay sample fall in exactly the same position on the disk in two consecutive runs for $\mathrm{H}=100 \mathrm{~cm}$.

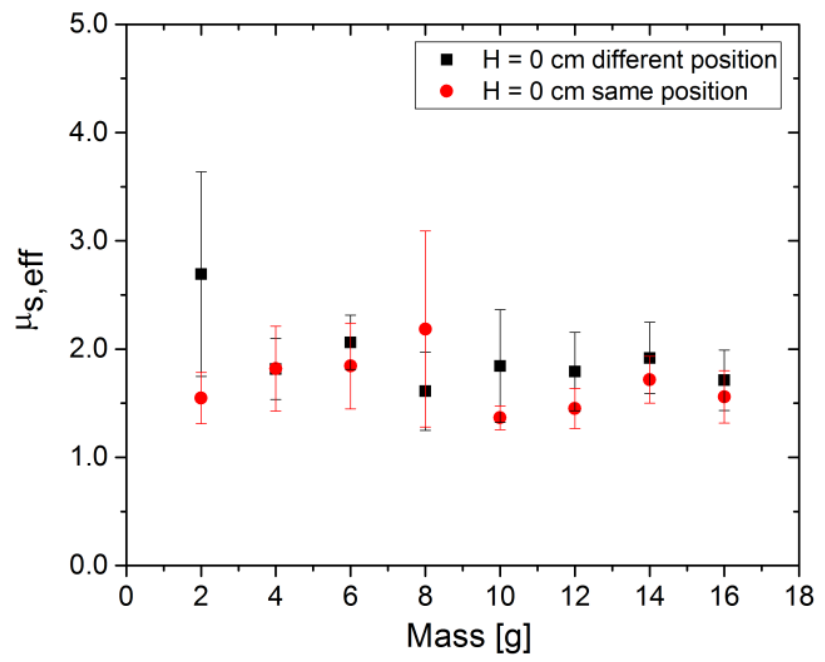

Figure 9. Effective static friction coefficient for different clay lump masses and $\mathrm{h}=0$ $\mathrm{cm}$ (surface: galvanized mild steel). The wet clay samples were re-positioned in a different position (black, $\mathrm{T}=24.7-26.5^{\circ} \mathrm{C}, \mathrm{RH}=44.8-54.0 \%, 5$ repetitions) or in the same position (red, $\mathrm{T}=24.2-26.1^{\circ} \mathrm{C}, \mathrm{RH}=42.8-46.4 \%, 5$ repetitions) on the disk.

\section{Effect of surface material}

In figure 10, measurements with the mild steel surface and the Accolan (Teflon) surface are shown. Teflon is, in general, a low stick material and as such may be considered the best possible surface for antistick purposes. The rougness of the two surfaces is practically the same (about $8 \mu \mathrm{m}$ ), allowing for isolation of the effect on the friction coeffient of the surface material (assuming that the structures providing the average roughness are approximately equal for the two surfaces). It is apparent 
from Fig. 10 that the friction coefficient of mild steel is about twice the value of Accolan for clay lump masses above $8 \mathrm{~g}$. Therefore, material type does play a role for the antistick property of a surface.

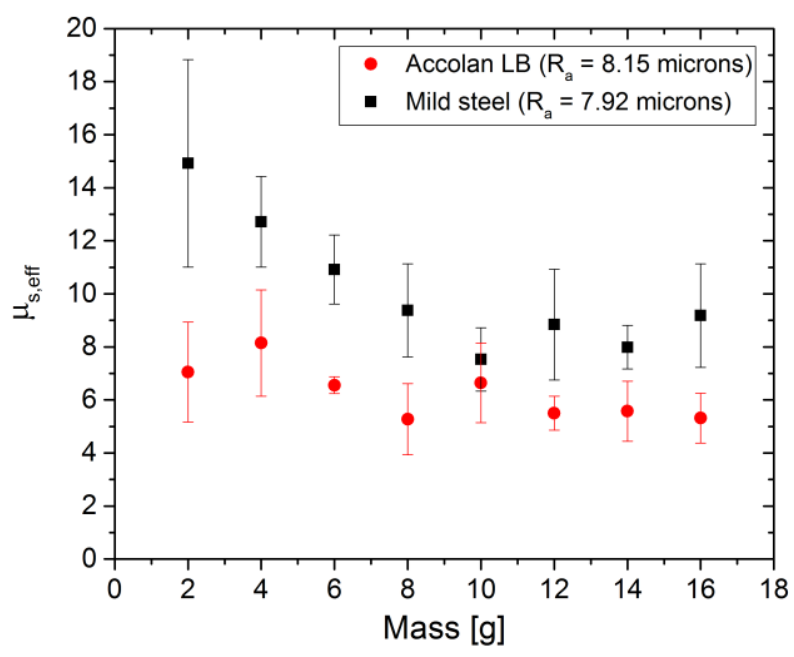

Figure 10. Effective static friction coefficient versus clay lump mass $(\mathrm{h}=100 \mathrm{~cm})$.

Teflon $\left(\mathrm{T}=22.4-26.4{ }^{\circ} \mathrm{C}, \mathrm{RH}=35.1-47.2 \%, 5\right.$ repetitions $)$ and mild steel $(\mathrm{T}=23.6-27.5$ ${ }^{\circ} \mathrm{C}, \mathrm{RH}=28.0-47.7 \%, 5$ repetitions).

\section{The combined effect of surface material and roughness}

The Matrox lining is made of polyethylene and has a very low roughness (about 1 $\mu \mathrm{m})$. This lining is a commercial product already in use in some existing cement plants. In Fig. 11, the friction coeffient measurements for Matrox lining has been compared to those of Accolan LB. It can be seen that the performance of Matrox is able to match that of the Teflon-based Accolan LB coating. This means that even though Matrox is a less hydrophobic material (see later), the very low roughness of the Matrox lining counteracts this effect. 


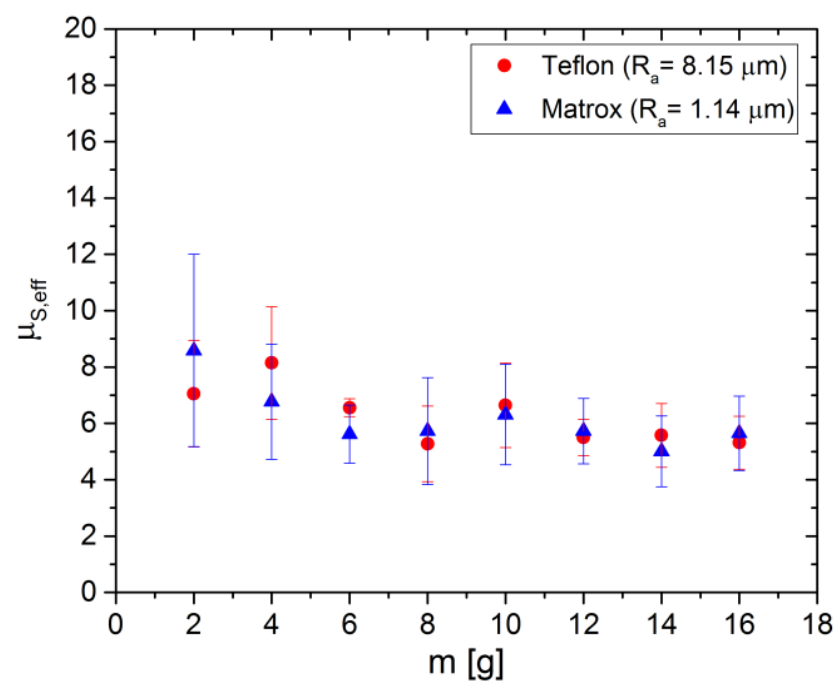

Figure 11. Effective static friction coefficient versus clay lump mass $(\mathrm{h}=100 \mathrm{~cm})$.

Teflon (Accolan 2G54, $\mathrm{T}=22.4-26.4{ }^{\circ} \mathrm{C}, \mathrm{RH}=35.1-47.2 \%, 5$ repetitions) and Matrox $\left(\mathrm{T}=21.7-25.0^{\circ} \mathrm{C}, \mathrm{RH}=41.0-62.7 \%, 5\right.$ repetitions $)$.

Finally, in Fig. 12, the measurements for all eight surfaces are shown.

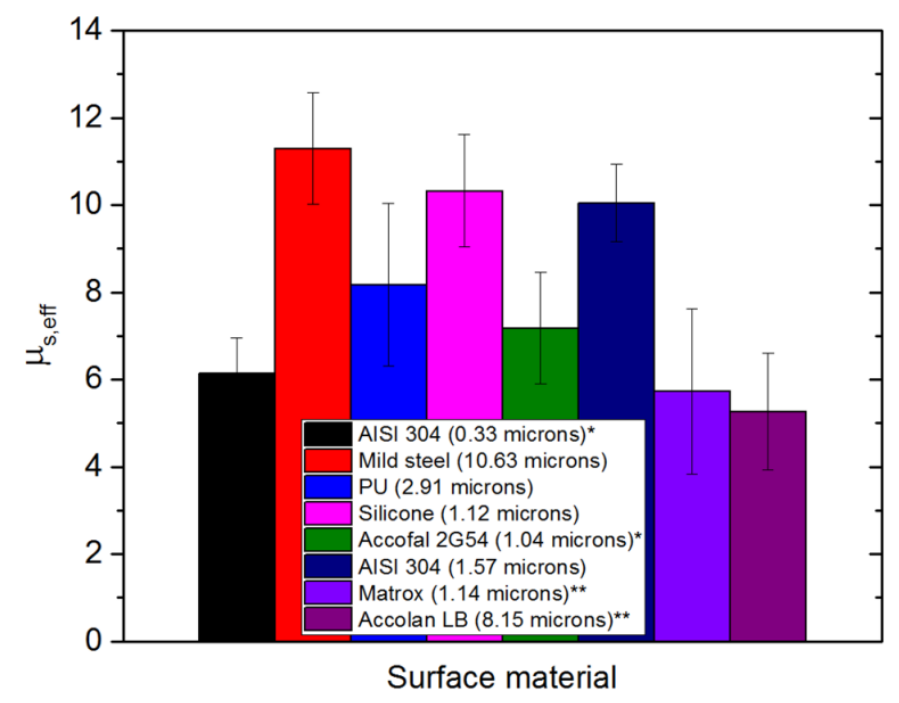

Figure 12. Effective static friction coefficient for different surface materials and roughness levels (the value indicated within brackets is the Ra value) for artificial Slantzy clay. AISI 304 is stainless steel. All the experiments were conducted for $\mathrm{m}=8.0 \mathrm{~g}$ and $\mathrm{h}=100 \mathrm{~cm}$. The single asterisk means that the data were slightly 
overestimated, due to uncertainty in the detection of the clay lump detachment time needed to calculate the effective static friction coefficient, i.e.the onset of the detachment of clay samples on those disks was difficult to detect accurately, which may have led to a slightly delayed detection (maximum 3 seconds). The double asterisk means that natural Slantzy clay (as opposed to mixing dried Slanzy clay samples with water) was used.

The results can be divived into two groups; the best performing ones (polished stainless steel, Accolan 2G54 (Teflon) coating, Matrox and PU), and the less good surfaces (mild steel, silicone coating, and stainless steel). However, the experimental uncertainties must be kept in mind; in fact, it is only possible to see a significant difference between the three best and the three worst performing surfaces.

Surprisingly, the differences between the two groups are not great, mostly a factor of about two. In addition, the silicone coatings, which are also used on ships as fouling release coatings for protection against biofouling, were expected to fall in the best performing group. Presently, we are unable to explain this last result, but it must be kept in mind that seawater contact (when used on a ship hull) influences the surface properties of fouling release coatings. Interestingly, polished stainless steel can match the performance of the Matrox lining and the Teflon (Accofal 2G54) coating, and the surface energy must therefore be of secondary importantance. Based on the results, it may be an option to use thin sheets of polished steel for antistick purposes in selected areas of cement plants. For the two Teflon based surfaces (Accolan LB and Accofal 2G54), the roughness has a smaller effect than the actual surface material; the high roughness coating falls in the group of best performing surfaces. 


\section{Contact angle measurements}

For further chacterization of the surfaces, apparent contact angles were measured. The results for three different positions on each surface are provided in Table 5 along with average roughness values. Contact angles above $90^{\circ}$ are in general considered hydrophobic and above $150^{\circ}$ the surfaces are superhydrophobic.

A positional effect is seen for PU, Matrox and Accoplan LB pointing to less homogeneous surfaces than the remaing ones. It can also be seen that the PU coating has the highest apparent contact angle, followed by Accofal, Silicone, Matrox, and Accolan LB. Due to size limitations in the measuring equipment, the steel surfaces were not measured, but they are all expected to be hydrophilic (high energy) surfaces with low contact angles (as long as they are clean). The high contact angle measured for the PU coating can be attributed to special (confidential) hydrophobic fillers employed in this work to improve the antistick properties of the coating.

The apparent contact angles contain contributions from both roughness and surface chemistry and it is not possible to accurately separate the effects of the two parameters without resorting to atomic force microscopy [11]. However, as seen in Table 5, the average roughness values for all coatings (except Accolan LB) and Matrox surfaces are all of the order of $1 \mu \mathrm{m}$ and the effect from roughess can probably be assumed to be more or less the same for the coatings. This means that the surface chemistry (binder type) of the coatings is approximately reflected in the data shown in Fig. 12 and in Table 5. As shown in Fig. 13, there does not seem to be a correlation between static effective friction coefficients and the apparent contact angles of the coatings and the Matrox lining.

The results demonstrate that in the case of wet clay, neither roughness nor chemistry can be used in an efficient way to control the anti-stick properties of a surface. Not 
even a superhydrophobic coating (consider extrapolation of the contact angle data in Fig. 13 from 133 to $150^{\circ}$ ) can be expected to provide anti-stick properties; in fact high contact angles appear to increase the friction coefficient. We therefore speculate that wet clay adheres to surfaces in a very special way, and that capillary suction (see section 1.1) is a good mechanistic candidate, but this was not investigated any further in the present work.

Table 5. Apparent advancing contact angles for the coated surfaces at three different positions. The standard deviations are based on three repetitive measurements.

\begin{tabular}{|l|c|c|c|c|}
\hline \multicolumn{1}{|c|}{ Surface } & Contact & Contact & Contact & Average \\
& angle $\left(^{\circ}\right)$, & angle $\left.{ }^{\circ}\right)$, & angle ( $\left.{ }^{\circ}\right)$, & roughness \\
& position 1 & position 2 & position 3 & of surface, \\
& & & & Ra ( $\boldsymbol{\mu m})$ \\
\hline Polyurethane (PU) & $138 \pm 8$ & $125 \pm 3$ & $133.9 \pm 3.4$ & 2.91 \\
\hline Silicone & $108.5 \pm 1.9$ & $106 \pm 13$ & $109 \pm 14$ & 1.12 \\
\hline Accofal 2G54 (Teflon- & $113 \pm 0.75$ & $112.9 \pm 1.37$ & $113 \pm 9$ & 1.04 \\
\hline based) & & & & \\
\hline Matrox (polyethylene- & $73.55 \pm 0.08$ & $80.68 \pm 1.37$ & $84.4 \pm 0.17$ & 1.14 \\
\hline based) & & & & \\
\hline Accolan LB (Teflon- & $86 \pm 1.4$ & $96 \pm 1.5$ & $102.4 \pm 0.3$ & \\
\hline based) & & & & \\
\hline
\end{tabular}




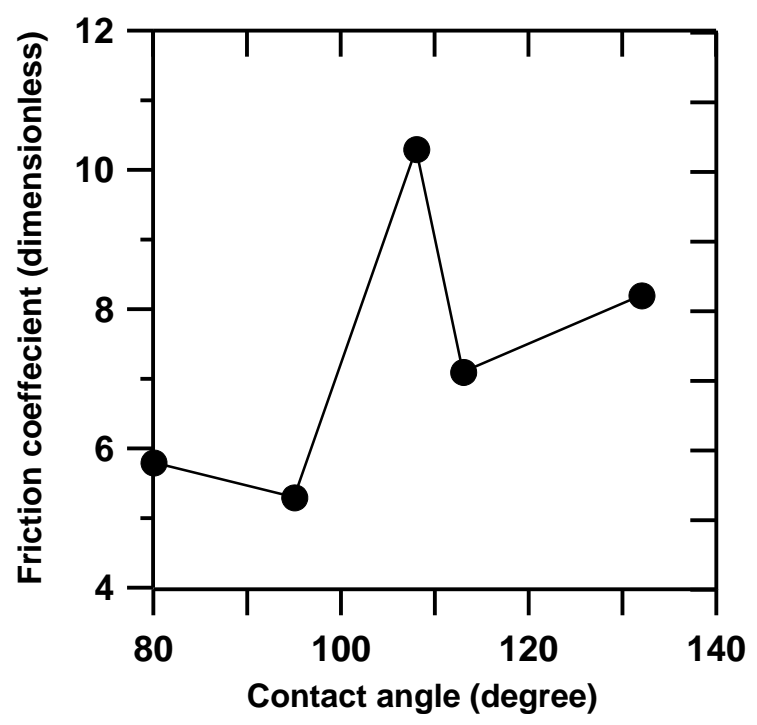

Figure 13. Effective static friction coefficient for the surfaces in Table 5 as a function of the apparent advancing contact angle. Uncertainties are provided in Fig. 12 and Table 5.

\section{Conclusions}

A pilot plant that enables the measurement of wet clay antistick properties of metal, lining, and coating surfaces was presented. The physical situation simulated is that of a wall in the so-called splashing zone inside transfer chutes (between assembly belts) in cement producing plants. The abrasion pressure in this zone is significantly lower than that in the high impact zone, where most clay and rocks on the assembly belt will come in direct contact with the wall.

The results obtained show that polished stainless steel, Matrox lining or Teflon-based coatings would be the best choice from a tribological point of view. In practice, however, other considerations, such as cost and material durability, must be taken into account and the best choice at present seems to be the Matrox lining or a polished steel surface. 
Keeping in mind that Teflon-based coatings with low roughness values were not able to provide superior antistick properties, it seems unlikely that coatings can be formulated to solve the challenge with stickiness of wet clay.

\section{Acknowledgements}

The authors wish to thank Johan Scholl for his help with the contact angle measurements, Jakob Eltzholtz, for the ICP and XRF analyses of Slantzy Clay, and Kasper Skov Mørk and Ion Marius Sivebæk for discussions on the setup design and implementation. This work was part of the research platform 'Minerals and Cement Process Technology - MiCeTech' funded by Innovation Fund Denmark, FLSmidth A/S, Hempel A/S, The Hempel Foundation, and The Technical University of Denmark. The research was conducted at the Center for Coatings Science and Technology (CoaST) at DTU.

\section{Nomenclature}

$\begin{array}{ll}\mathrm{F} & \text { force }(\mathrm{N}) \\ \mathrm{g} & \text { gravitational acceleration }\left(\mathrm{m} / \mathrm{s}^{2}\right) \\ \mathrm{m} & \text { mass of clay lump }(\mathrm{g}) \\ \mathrm{N} & \text { Normal force }(\mathrm{N}) \\ \mathrm{DFT} & \text { dry film thickness }(\mathrm{m}) \\ \mathrm{r} & \text { radial position }(\mathrm{m}) \\ \mathrm{Ra} & \text { arithmetic average roughness, }(\mathrm{m}) \\ \mathrm{t} & \text { time (s) } \\ v & \text { impact velocity of clay lump }(\mathrm{m} / \mathrm{s}) \\ \mathrm{XRD} & \text { X-ray diffraction }\end{array}$




\section{Greek}
$\alpha$
constant angular acceleration $\left(\mathrm{s}^{-1}\right)$
$\omega \quad$ angular velocity $\left(\mathrm{s}^{-1}\right)$
$\mu_{\mathrm{s}, \mathrm{eff}} \quad$ effective static friction coefficient (dimensionless)

\section{References}

[1] E.R. Fountaine, Investigations into the mechanism of soil adhesion, Journal of Soil Science. 5 (1954), 251-263.

[2] N. Mitarai, F. Nori, Wet granular materials, Advances in physics. 55(2006), 1-45.

[3] A. Kooistra, P.N.W. Verhoef, W. Broere, D.J.M. Ngan-Tillard, A.F. van Tol, Appraisal of stickiness of natural clays from laboratory tests, Proceedings of the National Symposium of Engineering Geology and Infrastructure, Delft, Netherlands, 1998, 101-113.

[4] M. Feligha, F. Hammoud, M. Belachia, M.S. Nouaouria, Experimental Investigation of Frictional Behavior Between Cohesive Soils and Solid Materials Using Direct Shear Apparatus, Geotechnical and Geological Engineering. 34(2016), $567-578$.

[5] I. Littleton, An Experimental Study of the Adhesion between clay and steel, Journal of Terramechanics. 13(1976), 141-152.

[6] Y. Tsubakihara, H. Kishida, T. Nishiyama, Friction between cohesive soils and steel, Soils and Foundations. 33(1993), 145-156. 
[7] A.R. Zimnik, L.R. van Baalen, P.N.W. Verhoef, D.J.M. Ngan-Tillard, The adherence of clay to steel surfaces, Proceedings of the International Conference on Geotechnical and Geological Engineering, Melbourne, Australia, 2000, 1-6.

[8] R. Zumsteg, A.M. Puzrin, Stickiness and adhesion of conditioned clay pastes, Tunnelling and Underground Space Technology. 31(2012), 86-96.

[9] V. L. Popov, Contact Mechanics and Friction, first edition, Springer-Verlag Berlin Heidelberg, 2010.

[10] E. Rabinowicz, Friction and wear of materials, second edition, John Wiley \& Sons, inc., 1995.

[11] J.R. Svendsen, Kontogeorgis, G., Kiil, S., Weinell, C.E., Grønlund, M., Adhesion between coating layers based on epoxy and silicone, J. Colloid Interface Science, 316, (2007) 678-686. 